\title{
AUDIT KOMUNIKASI PEMASARAN MOTION RADIO: ANALISIS MEDIA ORGANIZATIONAL MODEL MELALUI METODE SOSTAC
}

\author{
Anathasia Citra \\ Jurusan Marketing Communication, Fakultas Ekonomi dan Komunikasi, BINUS University \\ Jln. K.H. Syahdan No. 9, Palmerah, Jakarta Barat 11480 \\ anathasia_c@yahoo.com
}

\begin{abstract}
This research is about the marketing communication audit of Otomotion FM that re-branding into Motion Radio by analyzing Media Organizational Model through SOSTAC method, Situation-ObjectiveStrategy-Tactics-Action-Control. This research is also to see the contribution of Reputation Marketing Strategy to achieve the goals of re-branding, This is a descriptive research with qualitative approach by using in depth interviews by using marketing communication audit format that operates Media Organizational Model and SOSTAC. The result of Marketing Communication Audit shows the effectiveness, strength and weakness of the previous and ongoing marketing communication as a guide to make marketing communications plan and as an input to the marketing communication study because increasingly competitive media business.
\end{abstract}

Keywords: rebranding, reputation marketing, marketing communication audit, SOSTAC

\begin{abstract}
ABSTRAK
Penelitian ini mengenai audit komunikasi pemasaran Otomotion FM yang melakukan rebranding menjadi Motion Radio dengan menganalisis Media Organizational Model melalui metode SOSTAC yaitu Situation-Objective-Strategy-Action-Control. Penelitian ini juga melihat kontribusi strategi Reputation Marketing dalam membantu tujuan rebranding yaitu merubah image dan memperluas segmentasi pendengar. Penelitian menggunakan pendekatan kualitatif dengan sifat penelitian deskriptif dan menggunakan wawancara mendalam melalui format audit komunikasi pemasaran dengan mengoperasionalkan Media Organizational Model dan SOSTAC. Hasil audit komunikasi mengungkap efektivitas, kekuatan dan kelemahan komunikasi pemasaran yang telah dan sedang berlangsung sebagai pedoman pembuatan perencanaan komunikasi pemasaran serta masukan bagi studi komunikasi pemasaran karena makin kompetitifnya bisnis media.
\end{abstract}

Kata kunci: rebranding, reputation marketing, audit komunikasi pemasaran, SOSTAC 


\section{PENDAHULUAN}

Ketatnya persaingan radio komersil di Jakarta khususnya, membuat pengelola radio harus pandai dalam berstrategi untuk mempengaruhi dan berusaha memenuhi kebutuhan konsumennya. Perkembangan jumlah radio di Indonesia sungguh menakjubkan. Awal tahun '90an tercatat 451 radio yang menjadi anggota Persatuan Radio Siaran Swasta Indonesia (PRSSNI). Jumlah itu meningkat hampir 2 kali lipat menjadi 847 pada tahun 2007. Jika ditambah dengan radio yang tidak terdaftar sebagai anggota PRSSNI dan radio komunitas, diperkirakan jumlah radio di Indonesia bisa mencapai lebih dari 1200 radio siaran. Sementara, jumlah radio komersil dengan frekuensi fm yang bersaing di Jakarta saat ini menurut data PRSSNI sampai tahun 2009 bertambah menjadi 47 radio dengan segmentasi pendengar yang berbeda-beda berdasarkan usia, status sosial dan jenis musik yang diputar (Santosa, 2008).

Otomotion FM yang mulai mengudara di Juli 2005 dengan konsep sebagai radio otomotif yang ditujukan untuk mayoritas pendengar pria, tidak berhasil mendapatkan khalayak atau profit yang menjadi tujuannya, oleh sebab itu manajemen merasa perlu melakukan rebranding pada Maret 2009. Rebranding yang dilakukan, antara lain perubahan nama menjadi Motion Radio, perubahan logo, perubahan format musik, perubahan penyiar, perubahan gaya siaran, perubahan jingle, perubahan strategi promosi dan sebagainya.

Rebranding ini bertujuan untuk menghilangkan image brand sebelumnya, meningkatkan jumlah pendengar, peningkatan brand awareness dan juga agar bisa memenangkan kompetisi dalam pasar pendengar radio di Jakarta khususnya untuk segmentasi profesional muda yang mengedepankan musik dan gaya hidup sebagai tujuan utamanya. Ada beberapa radio dengan segmentasi seperti ini di Jakarta khususnya (lihat lampiran), tetapi Hard Rock FM, KIS FM, Indika FM dan JAK FM yang diperhitungkan oleh manajemen Motion Radio sebagai kompetitor utama. Profit menjadi tujuan jangka panjang jika tujuan-tujuan rebranding tersebut bisa berhasil.

Persaingan radio dalam merebut pasar dan mendapat profit memerlukan strategi komunikasi pemasaran yang tepat dan efektif. Sebagai sebuah perusahaan yang memproduksi jasa informasi dan juga hiburan, stasiun radio juga memerlukan tahapan-tahapan strategi seperti layaknya perusahaan lain, mulai dari riset, penentuan target pasar, penentuan taktik produksi, promosi hingga evaluasi produk. Komunikasi pemasaran menjadi penting terutama untuk radio yang segmented agar dapat menyasar target pendengar yang tepat, memperoleh brand postioning yang tepat dan meningkatkan brand awareness.

Audit komunikasi pemasaran biasanya dilakukan untuk mengukur efektivitas suatu kegiatan atau program komunikasi, jika tidak dilakukan proses audit komunikasi pemasaran, maka perusahaan tidak dapat mengetahui berfungsi atau tidaknya strategi komunikasi pemasaran yang sedang dijalankan. Oleh sebab itu, audit stratetegi komunikasi pemasaran penting dikaji untuk menggambarkan bagaimana strategi komunikasi pemasaran yang tepat, khususnya untuk radio siaran yang segmented.

Penelitian ini penting khususnya untuk bisnis media karena bisnis media berbeda dengan bisnis konsumen lainnya. Bisnis media mendapatkan profitnya dari pengiklan dan bukan dari konsumen. Pengiklan memasang iklan di media biasanya tergantung pada rating dari media tersebut yang berdasar hasil survey (misalnya Nielsen Media Research).

Pergantian sebuah nama media, khususnya media radio atau dalam komunikasi pemasaran disebut dengan istilah rebranding adalah suatu yang sangat langka terjadi, karena perubahan nama, sama artinya dengan membangun radio baru. Tetapi dalam kasus rebranding Otomotion FM menjadi Motion Radio, perubahan nama terjadi karena implikasi dari tuntutan-tuntuntan secara internal dan 
eksternal dalam suatu organisasi media, dalam hal ini Kompas Gramedia sebagai induk perusahaan dari Motion Radio dan juga pengiklan.

Rebranding dilakukan dengan maksud dan tujuan tertentu, ada proses yang melatarbelakangi kenapa dilakukan rebranding, hal inilah yang akan dikaji peneliti secara mendalam. Rebranding merupakan sebuah proses dan butuh investasi yang tidak sedikit, oleh sebab itu diperlukan perencanaan komunikasi pemasaran yang tepat yang dapat dilihat dari hasil audit komunikasi pemasaran sebelumnya sehingga kegagalan sebelumnya dapat dihindari dan dapat diminimalisir.

Dalam melakukan audit komunikasi pemasaran, peneliti ingin mengkajinya dengan konsep model organisasi media (media organizational model). Media Organizational Model dipakai karena model ini bisa menjelaskan dinamika perusahaan media sebagai perusahaan bisnis yang dipengaruhi struktur pasar (market structure) dan juga organisasi media (media organizational) tersebut (McQuail, 1992).

Oleh karena itu bila peneliti telusuri dari pokok permasalahan, maka pertanyaan penelitiannya adalah: (1) apakah dengan rebranding dari sebuah radio segmented dapat merubah image brand sebelumnya, meningkatkan brand awareness dan memperluas segmentasi pasar; (2) bagaimana strategi Reputation Marketing dapat membantu mencapai tujuan rebranding radio yang segmented; (3) bagaimana gambaran komunikasi pemasaran yang dilakukan radio yang melakukan rebranding yang diperoleh dari hasil audit strategi komunikasi pemasarannya dengan Media Organizational Model melalui metode SOSTAC; (4) bagaimana hasil audit komunikasi pemasaran melalui analisis Media Organization Model melalui metode SOSTAC dapat membantu pembuatan rencana komunikasi pemasaran (Marketing Communications Plan) untuk Motion Radio di tahun 2011?

\section{METODE}

Penelitian ini menggunakan pendekatan kualitatif. Untuk mengungkap permasalahan yang ada dalam penelitian ini, peneliti melihatnya dari perspektif yang sifatnya deskriptif. Dalam penelitian ini peneliti mencoba memaparkan serta menggambarkan aktivitas komunikasi pemasaran yang dilakukan oleh Otomotion FM dan juga setelah dilakukan rebranding menjadi Motion Radio lewat suatu proses audit komunikasi pemasaran. Disamping mengamati kegiatan komunikasi pemasaran yang dilakukan, juga akan dibahas kegiatan lainnya yaitu kegiatan yang dilakukan pada divisi program radio, karena konsep dan warna program radio adalah sebagai bagian penting dari rebranding yang dilakukan perusahaan.

Dalam penelitian kualitatif ini penelti menggunakan unit analisis adalah Motion Radio sebagai organisasi media penyiaran, sementara unit observasinya adalah para informan terdiri dari Managing Director, Program Director, Sales\&Marketing Director, Promotion Manager mereka adalah orangorang dalam organisasi internal media dan eksternal media yang berhubungan langsung dalam proses rebranding dan komunikasi pemasaran yang terjadi di Otomotion FM dan setelah rebranding menjadi Motion Radio dari Juli 2005 Sampai Februari 2010. Proses terakhir adalah pembuatan laporan hasil penelitian dalam bentuk tulisan ilmiah.

\section{HASIL DAN PEMBAHASAN}

Motion Radio hadir dengan identitas nama yang berbeda dari sebelumnya yaitu Otomotion FM, mengenai perubahan nama, kelima informan dari manajemen Motion Radio, umumnya memberikan jawaban yang sama. Latar belakang perubahan nama karena dengan menggunakan nama Otomotion FM menyebabkan radio ini terlalu segmented, hanya menyasar kalangan tertentu yang 
jumlahnya tidak banyak. Selain itu format radio Otomotif tidak mendapat respon yang baik atau kurang disukai oleh masyarakat awam. Hal ini berdampak kepada profit dari para pengiklan, karena dengan nama Otomotion FM, brand image yang melekat adalah radio tersebut adalah radio otomotif sehingga pengiklan hanya terbatas pada produsen produk yang berhubungan dengan otomotif seperti ATPM, Oli, event otomotif dan produk untuk pria umumnya, sedangkan variasi produk lainnya misalnya produk consumer goods ataupun produk wanita tidak bisa beriklan karena tidak sesuai.

Oleh sebab itu pihak internal media memutuskan melakukan rebranding, selain itu pihak pengiklan juga menyatakan dengan nama Otomotion FM dengan format radio otomotif, tidak sesuai dengan produk mereka untuk beriklan, karena hanya terbatas pada iklan-iklan yang berhubungan dengan dunia otomotif. Menurut Pringle (1991) rebranding tidak terlepas dari kondisi internal dan eksternal media, karena media penyiaran pada dasarnya harus mampu melaksanakan berbagai fungsi, antara lain fungsinya sebagai media untuk beriklan, media hiburan, media informasi dan media pelayanan. Untuk mampu melaksanakan seluruh fungsi tersebut sekaligus dapat memenuhi kepentingan pemasang iklan, audiens serta pemilik dan karyawan

Brand image yang kuat pada brand sebelumnya yaitu Radio Otomotif diakibatkan karena nama yang sudah identik dengan nama Otomotif, dari bentuk logo dan dari isi program-nya. Walaupun demikian, dengan difrensiasi sebagai produk niche dibanding radio-radio kompetitor, image Otomotif dengan cepat melekat di masyarakat walaupun radio tersebut baru saja berdiri. Rebranding yang dilakukan Motion Radio sekaligus repositioning, karena ingin membuat ulang posisi brand di benak pendengar dengan image baru, salah satu yang terpenting adalah menghilangkan konotasi Radio Otomotif.

Oleh karena itu dapat dilihat, rebranding yang dilakukan tidak hanya sekedar perubahan nama, tetapi isi program dan strategi komunikasi pemasarannya sudah berubah, karena brand lama dianggap tidak bisa diterima oleh masyarakat umum. Seperti menurut Jetkins (2004), rebranding dengan perubahan nama bisa terjadi karena perusahaan tidak saja berubah sifat aktivitasnya, akan tetapi juga bisa berubah karena identitasnya juga berubah. artinya, identitas yang lama sudah tidak lagi sesuai dengan kondisi lingkungan yang baru

Para informan juga menyatakan bahwa dengan rebranding ini diharapkan bisa meningkatkan profit, walaupun sampai peneletian ini selesai, profit yang diharapkan belum signifikan alias tidak jauh berbeda jumlahnya dengan sebelum rebranding. Walaupun demikian, profit adalah tujuan jangka panjang, karena rebranding membutuhkan proses yang tidak sebentar, sementara saat penelitian ini selesai, rebranding berjalan belum sampai 2 tahun. Tujuan utama dari rebranding ini adalah, menghilangkan image brand sebelumnya, meningkatkan brand awareness dan memperluas segmen.

Rebranding merupakan sebuah proses, untuk mencapai tujuan dari rebranding yang disebutkan oleh informan, yaitu menghilangkan image "Radio Otomotif" meningkatkan brand awareness dan memperluas segmen, maka ada banyak strategi komunikasi pemasaran yang dibenahi guna menyasar segmentasi yang dituju sejalan dengan rebranding, oleh sebab itu diperlukan inovasi dan kreatifitas untuk etidaknya meningkatkan brand awareness. Namun, kegiatan komunikasi pemasaran yang dilakukan setelah rebranding disyaratkan untuk sedapat mungkin tidak mengeluarkan cost (biaya), jadi komunikasi pemasaran yang dilaksanakan haruslah didukung atau dibiayai oleh sponsor ataupun perusahaan induk, yaitu Kompas Gramedia.

Jadi, rebranding ini dilakukan dengan 3 alasan, yaitu (1) menghilangkan image radio otomotif, (2) meningkatkan brand awareness (3) merebut segmentasi yang lebih luas secara status ekonomi sosial dan demografi dan tujuan jangka panjangnya yaitu meningkatkan profit dengan menarik pengiklan dari produk produk yang tidak lagi terbatas pada produk otomotif. 
Berdasarkan data primer dan sekunder, tujuan rebranding dengan penggunaan nama baru, strategi komunikasi pemasaran yang baru, perubahan format program, musik dan gaya penyiar telah menjukkan ke arah keberhasilan dari tujuan rebranding, seperti makin memudarnya image otomotif tergantikan dengan image sebagai radio musik dan gaya hidup, berubahnya karakteristik pendengar dimana saat ini pendengar laki-laki dan wanita seimbang persentase-nya, sementara sebelum rebranding mayoritas pria, brand awareness belum diukur secara valid (data nielsen) namun berdasarkan survei internal, telah terjadi sedikit peningkatan tetapi masih rendah dibanding kompetitor. Untuk jumlah pendengar, perusahaan menghitungnya dari jumlah sms yang masuk yang terus meningkat, walaupun demikian untuk jumlah pasti jumlah pendengar belum terukur oleh survei Nielsen.

Sosialisasi dan komunikasi rebranding ini masih minim karena terbentur tidak adanya anggaran untuk berpromosi, tanpa sosialisasi rebranding akan sulit mencapai tujuan, Motion Radio harus memastikan sosialisasi ini terutama lewat kegiatan komunikasi pemasaran yang inovatif dan kreatif.

Akibat terbatasnya anggaran yang dimiliki perusahaan untuk melakukan komunikasi pemasaran terutama mengkomunikasikan nama baru, baik kepada pengiklan maupun masyarakat umumnya, maka digunakanlah reputation marketing.

Pada umumnya para informan yang berasal dari manajemen Motion Radio menyebutkan bahwa dengan menggunakan nama besar Kompas Gramedia dalam hampir seluruh aspek kegiatan komunikasi pemasaran pasca rebranding menjadi Motion Radio adalah menguntungkan buat efektifitas komunikasi pemasaran Motion Radio ke pendengar maupun pengiklan.

Kompas Gramedia adalah perusahaan media yang sudah lama berdiri dan mempunyai kredibilitas tinggi, tetapi hal ini menjadi dilematis, karena media-media dari Kompas Gramedia yang berhasil adalah dari media-media cetaknya. Sementara untuk media radio, Kompas Gramedia sukses dengan Radio Sonora. Namun Radio Sonora, juga merupakan perusahaan yang sudah lama berdiri sehingga sudah mempunyai pendengar setia. Ketika Otomotion FM rebranding menjadi Motion Radio dan menyasar kalangan masa kini dan dinamis tidak serta merta mendapatkan reputasi yang sama dengan Kompas Gramedia, karena sekarang masyarakat makin peka dan bahkan tidak peduli dengan reputasi perusahaan yang membawahinya. Walaupun demikan, lebih mudah dan lebih efisien untuk Motion Radio melaksanakan komunikasi pemasarannya karena bisa bersinergi dengan Kompas Gramedia, dan lebih mudah bersosialisasi dengan klien khususnya karena menebeng nama Kompas Gramedia.

Oleh sebab itu, Motion Radio harus terus melakukan inovasi, terlebih media radio adalah media yang dinamis dimana perkembangan selera pasar terus bergulir. Marconi (2002) menyebut: “A company's longevity, when considered in term of its reputation, sometimes presents the proverbial two-sided coin. Sometimes a reputation for being an old, solid, established company is a good thing. But, the natural inclination of both consumers and companies to try the newest, freshest version of almost anything: that new is good, older is bad. A successful defense adds to the established company's reputation as a winner. A loss of market share, invites competitors and critics: the established name as being "on the decline" or worse "the choice of yesterday. Who cares how long a company has been in business? More specifically, why should anyone care?"

Berkaitan dengan reputasi, setelah rebranding, manajemen melakukan pembenahan dari sisi program, oleh sebab itu perusahaan memutuskan memakai penyiar yang sudah mempunyai nama dan massa yang besar, yaitu Arie Dagienkz, tentunya hal ini berhubungan dengan strategi komunikasi pemasaran Motion Radio. 
Jadi implikasi penggunaan nama besar Kompas Gramedia dalam strategi komunikasi pemasaran Motion Radio, antara lain: (1) efisiensi biaya dan meminimalisasi cost promosi yang dikeluarkan Motion Radio; (2) kredibilitas Kompas Gramedia mengangkat brand image Motion Radio di mata klien dan masyarakat; (3) meningkatkan brand awareness, karena reputasi penyiar prime time (Arie Dagienkz) sudah mempunyai massa dan juga meningkatkan nilai jual program prime time Motion Radio kepada klien; (4) organisasi media massa juga dilihat sebagai perusahaan bisnis (business firm). Selayaknya sebuah perusahaan bisnis, profit pastilah yang menjadi tujuan. Profit menjadi tujuan jangka panjang, setelah tujuan rebranding. Oleh sebab itu untuk melihat industri media dan apa yang terjadi di pasarnya, dilakukan Audit Komunikasi Pemasaran dengan menganalisis Media Organizational Model melalui metode SOSTAC.

(5) Analisis strategi komunikasi pemasaran dengan Audit Komunikasi Pemasaran dengan Analisis Media Organization Model melalui metode SOSTAC, perusahaan dapat dengan mudah mengidentifikasi permasalahan yang ada, apalagi perusahaan ini adalah sebuah perusahaan media (radio) yang melakukan rebranding. Dengan memecahkan isu pemasaran, mengetahui kondisi perusahaan, melihat penegelolaan organisasi media, melihat kinerja dari organisasi media dan mengevaluasi kegiatan komunikasi pemasaran yang sudah berlangsung, dapat dijadikan acuan untuk pembuatan rencana komunikasi pemasaran (Marketing Communications Plan) terutama untuk Motion Radio di tahun 2011.

(6) Cakupan marketing communications plan tersebut dengan melihat hasil analisis diatas, antara lain bisa menentukan tujuan komunikasi pemasaran, strategi bauran pemasaran (marketing mix), pricing strategy (commercial spot rate), Promotion Plan, Action Plan, Advertising Plan dan sebagainya.

\section{Audit Komunikasi Pemasaran Motion Radio dengan Metode SOSTAC}

Peneliti melakukan audit komunikasi pemasaran lewat wawancara mendalam, melihat data yang ada dan juga pengamatan dengan informan 1 (Hartanto, Managing Director Motion Radio), Informan 2 (Susy Triputranti, Sales\&Marketing Director Motion Radio) dan Informan 3 (Rio Rusminano, Promotion and Event Manager Motion Radio) ditambah dengan dukungan data perusahaan dan pengamatan peneliti. Audit komunikasi pemasaran berdasarkan analisis menggunakan metode SOSTAC, yaitu dari melihat Situation Analysis, Objective, Startegy, Tactic, Action dan Control.

\section{Situation Analysis}

Analisa situasi ini untuk melihat dimanakah posisi perusahaan tersebut berada (Where Are We Now?). Dalam kasus rebranding Otomotion FM menjadi Motion Radio, peneliti melihat kinerja atau performance perusahaan di 3 tahun terakhir yaitu Februari 2007-Februari 2010, antara lain dilihat dari pendapatan perusahaan.

Oleh sebab itu, berdasarkan situation analysis, peneliti mengambil pembelajaran, yaitu: (1) Otomotion FM berdiri dengan image sebagai radio otomotif, sehingga sulit untuk pengiklan masuk dari produk yang non-otomotif; (2) bergantung kepada pengiklan besar; (3) tidak merekrut orangorang-orang yang qualified di industri radio siaran, dipimpin oleh orang-orang dari platform media cetak tanpa pengalaman di dunia broadcast; (4) komunikasi pemasaran yang dilakukan tidak menyasar target yang tepat; (5) program tidak fokus, sehingga menyebabkan pergeseran segmentasi umur mayoritas pendengar (setelah sebelumnya 25-29, setelah rebranding bergeser menjadi 20-24 tahun); (6) tidak memiliki anggaran untuk melakukan sosialisasi rebranding dan komunikasi pemasaran brand baru kepada masyarakat; (7) tidak melakukukan evaluasi secara berkala, belum pernah dilakukan audit pemasaran ataupun audit komunikasi pemasaran. 


\section{Objective}

Peneliti mencoba mendalami apa yang menjadi objective dari Motion Radio, berdasarkan wawancara mendalam dengan Managing Director (Hartanto), profit memang jadi tuntutan tetapi tidak menjadi prioritas. Beliau menyatakan hal ini terkait dengan budaya Kompas Gramedia, yang menurut beliau adalah perusahaan yang bukan mencari keuntungan sebesar-besarnya, tetapi perusahaan yang ingin mencapai kredibilitas serta melindungi karyawannya, misalnya dengan jaminan kesejahteraan yang baik.

\section{Strategy}

Untuk mencapai objektif diatas, perusahaan harus menentukan strategi untuk mencapai objektif diatas. Strategi yang digunakan oleh Otomotion FM maupun setelah rebranding menjadi Motion Radio tidak belajar lebih cepat dari kompetitor, misalnya pemanfaatan teknologi. Motion Radio sedikit lebih lama menggunakan media social networking seperti twitter misalnya. Selain itu strategi komunikasi pemasaran terhambat oleh terbatasnya dana, tetapi Motion Radio didukung oleh perusahaan induknya, Kompas Gramedia, jadi dapat merumuskan strategi yang efisien walaupun mempunyai kendala pada dana.

\section{Tactics}

Taktik komunikasi pemasaran yang dilakukan untuk melaksanakan strategi komunikasi pemasaran diatas adalah dengan bekerja sama dengan Kompas Gramedia, antara lain dengan barter beriklan di media keluaran Kompas Gramedia seperti CHIC, Prevention, National Geographic, Otomotif, Kompas dan masih banyak lagi, selain itu juga berpartisipasi dalam event-event yang dilakukan Kompas Gramedia, dan melakukan komunikasi pemasaran dengan media yang gratis seperti social networking facebook dan twitter.

\section{Action}

Dalam setiap taktik komunikasi yang dilakukan khususnya untuk perencanaan komunikasi pemasaran 2011, Motion Radio perlu menyusun siapakah pelaksana dan penanggung jawab dari taktik-taktik komunikasi yang direncanakan.

\section{Control}

Untuk mengukur efektifitas kegiatan komunikasi pemasaran adalah dengan melakukan evaluasi. Otomotion FM dulunya tidak dievaluasi berkala, sementara Motion Radio sudah menerapkan evaluasi berkala yaitu setahun 2 kali pada bulan Juni dan Desember diumumkan hasil survei tiap semesternya, survei dilakukan oleh divisi riset Kompas Gramedia.

\section{PENUTUP}

Terjadinya rebranding dari Otomotion FM ke Motion Radio, tidak hanya sekedar perubahan nama belaka tetapi bagaimana membuat positioning baru dari produk sebelumnya (repositioning), karena produk sebelumnya dianggap gagal dan nama sebelumnya mempunyai konotasi yang kurang sesuai untuk bisnis radio yaitu radio Otomotif. Dengan rebranding ini termasuk perubahan nama Otomotion FM menjadi Motion Radio, image otomotif berangsur-angsur berubah menjadi radio dengan image radio musik dan gaya hidup (berdasarkan hasil Survei Internal Kompas Gramedia, Februari 2010). 
Dengan segmentasi sebagai Radio Musik dan Gaya Hidup, Motion Radio fokus pada peningkatan brand awareness untuk menambah jumlah pendengar. Untuk meningkatkan Brand Awareness, Motion Radio melakukan kegiatan komunikasi pemasaran, mulai dari berpromosi di media internal, menyelenggarkan event, memanfaatkan teknolog, dan sebagainya. Namun sayangnya, untuk menjalankan strategi komunikasi pemasaran terbentur mengenai tidak adanya anggaran. Brand awareness setelah rebranding menjadi Motion Radio berdasarkan survei internal, telah terjadi sedikit peningkatan tetapi masih sangat rendah dibanding kompetitor.

Dengan dilakukan rebranding, telah terlihat perubahan karakteristik pendengar dimana saat ini pendengar laki-laki dan wanita seimbang persentase-nya, sementara sebelum rebranding mayoritas pria. Segmentasi pendengar tidak terbatas pada pendengar mayoritas pria dan komunitas otomotif, namun lebih luas menyasar kalangan umum masyarakat kosmopolitan yang dinamis, career-oriented dan menjadikan radio musik dan gaya hidup sebagai bagian kesehariannya.

Terjadinya rebranding terutama disebabkan karena tidak tercapainya target profit yang diharapkan. Hal ini berkaitan dengan pemasukan yang didapatkan dari pengiklan. Berkaitan dengan nama Otomotion, membuat iklan yang masuk terbatas pada produk produk yang berhubungan dengan dunia otomotif, sementara produk otomotif umumnya tidak spending anggaran yang tinggi untuk beriklan di radio.

Dengan melihat hasil audit komunikasi pemasaran dengan menganalisis Media Organization Model melalui metode SOSTAC, Motion Radio dapat mengetahui keberhasilan program komunikasi yang diukur berdasarkan tujuan komunikasi tersebut (untuk mengubah image brand sebelumnya, meningkatkan brand awareness, dan memprluas pasar) Dari hasil audit dapat diketahui efektivitas pesan yang disampaikan sebelum dan sesudah rebranding untik dijadikan evaluasi karena dapat diketahui seberapa efisien bujet promosi yang dikeluarkan dan dapat dijadikan acuan untuk merancang strategi komunikasi baru (berikutnya) yang lebih baik

\section{Saran}

Motion Radio bisa melakukan Audit Komunikasi Pemasaran dengan metode SOSTAC, karena terbukti bisa menjelaskan dan menggambarkan kegiatan komunikasi pemasaran, serta melakukan evaluasi terhadap kegiatan Komunikasi pemasarannya.Hasil Audit Komunikasi Pemasaran bisa dimanfaatkan untuk merancang program komunikasi pemasaran (Marketing Communications Plan) Motion Radio untuk tahun 2011 sehingga hasilnya akan efektif dan bisa memenangkan kompetisi diantara stasiun radio dengan segmentasi sejenis

\section{DAFTAR PUSTAKA}

Berry, C., Pulford, A., \& Smith, P. R. (1997). Strategic marketing communication: New ways to build and integrate communication. UK: Kogan Page.

Bungin, B. (2001). Analisis data penelitian kualitatif. Jakarta: Rajagrafindo Persada.

Dowling, G. (1994). Creating corporate reputations: Identity, image and performance. UK: Oxford University Press.

Effendi, O. U. (1990). Radio siaran: Teori dan praktek. Bandung: Mandar Maju.

Hardjana, A. (2000). Audit komunikasi: Teori dan praktek. Jakarta: Grasindo. 
Keith, M. C. (1987). Radio programming: Consultacy and formatting. USA: Butterworth Publisher Stone Ham.

Marconi, J. (2002). Reputation marketing: Building and sustaining your organization's greatest asset. USA: McGraw-Hill.

McLeish, R. Radio production. Oxford, UK: Focal Press.

McQuail, D. (1992). Media performance: Mass communication and the public interest. London: SAGE.

McQuail, D. (1996). Teori komunikasi massa. (M. A. D. Aminuddin, terj.). Jakarta: Erlangga.

Santosa, A. (2008). Eksis di belantara radio. Diakses 10 Oktober 2009, dari http://radioclinic.com/2008/02/06/eksis-di-belantara-radio/

\section{RIWAYAT PENULIS}

Anathasia Citra lahir di Jakarta 6 Februari 1982. Penulis menyelesaikan pendidikan sarjana jurusan Komunikasi Massa di Universitas Indonesia Depok dengan gelar sarjana sosial (S.Sos) pada tahun 2006. Kemudian di tahun 2008, penulis melanjutkan pendididkan pada jenjang S2 di Magister Ilmu Komunikasi Unversitas Indonesia Depok, mayoring Manajemen Komunikasi. Penulis berhasil menyelesaikan pendidikan S2 pada tahun 2010. Saat ini penulis bekerja sebagai Faculty Member (FM) di Universitas Bina Nusantara. 